\title{
A Música como Ferramenta Pedagógica: Relato de uma Experiência nas Aulas de Física no Ensino Médio
}

\author{
Marcelo Máximo Purificação ${ }^{1}$; Elisângela Maura Catarino ${ }^{2}$; Maria Filomena Rodrigues Teixeira ${ }^{3}$; \\ Maria Luzia da Silva Santana ${ }^{4}$
}

Resumo: A sala de aula é um espaço marcado pela diversidade e que sofre influência dos aspectos in/ex (ternos). O presente trabalho tem por finalidade apresentar uma estratégia utilizada pelo professor de Física de uma escola estadual em Mineiros - Goiás, utilizando como ferramenta pedagógica o celular. É um estudo pautado na pedagogia histórico-crítica proposta por Gasparin e em relato de experiência. A metodologia utilizada proporcionou a execução de uma prática docente criativa, que ofuscou a presença do conflito, da indisciplina e trouxe para a sala de aula novos conhecimentos de Física a partir da música "Bicicletinha".

Palavras-chave: Estratégia de ensino. Interdisciplinaridade de conhecimentos. Aprendizagem por meio da música.

\section{Music as a Pedagogical Tool: Report of an Experience in Physics Classes in High School}

\begin{abstract}
The classroom is a space marked by diversity and influenced by the in / ex aspects (suits). The present work aims to present a strategy used by the physics teacher of a state school in Mineiros - Goiás, using as a pedagogical tool the cellular. It is a study based on the historical-critical pedagogy proposed by Gasparin and in an experience report. The methodology used provided the execution of a creative teaching practice, which overshadowed the presence of conflict, of indiscipline and brought to the classroom new knowledge of Physics from the song "Bicicletinha".
\end{abstract}

Keywords: Teaching strategy. Interdisciplinarity of knowledge. Learning through music.

\footnotetext{
${ }^{1}$ Pós-Doutor em Educação pela Universidade de Coimbra (UC/PT). Doutor em Ciências da Religião pela PUC-Goiás. Doutorando em Ensino pela UNIVATES. Professor Titular na SEDUCE e na UNIFIMES.

E-mail: maximo@unifimes.edu.br

${ }^{2}$ Pós-Doutora em Educação pela Escola Superior de Educação de Coimbra (ESEC/PT). Doutora em Ciências da Religião pela PUC-Goiás. Professora Titular na UNIFIMES. E-mail: maura@unifimes.edu.br

${ }^{3}$ Doutora em Didática (Universidade de Aveiro - Portugal). Coordenadora e Professora Adjunta na Escola Superior de Educação de Coimbra (ESEC-PT). E-mail: filomena.tx@gmail;

${ }^{4}$ Doutora e Mestra em Psicologia (Universidade Católica de Brasília- UCB); Especialista em Psicologia Social (Universidade Estadual de Santa Cruz-UESC) e em Educação e Promoção da Saúde (Universidade de Brasília - UNB) ; Psicóloga (Universidade Federal do Recôncavo da Bahia- UFRB); Licenciatura Plena em História (Universidade do Estado da Bahia UNEB) e em Pedagogia (Faculdades Alfredo Nasser - UNIFAN). É Professora Assistente na Universidade Federal de Mato Grosso do Sul - UFMS.
} 


\section{Introdução}

A educação na contemporaneidade é marcada pela diversidade, que faz da escola e da sala de aula espaços pluriculturais, por onde perpassam identidades, transitam diferentes tribos sociais e onde são promovidas vivências que integram aprendizagem, relações dialógicas, dilemas e conflitos. Aprender e ensinar em um ambiente de diversidade requer o aperfeiçoamento de práticas e estratégias que possam (re)direcionar tanto os docentes quanto seus alunos nesse processo. $\mathrm{O}$ presente trabalho tem por objetivo apresentar o relato de uma estratégia utilizada pelo professor de Física de uma escola estadual de Mineiros, GO, a partir de uma música, oriunda de um celular, cujo propósito óbvio, mas negado, era tumultuar o trabalho docente.

O uso das tecnologias móveis "nos atingiu como uma avalanche e envolve a todos" (MORAN, et al, 2013, p.8). Há quem diga que o seu uso em sala de aula não é benéfico ao processo de ensino-aprendizagem. Na rede estadual de educação de Goiás, o uso do celular é proibido e, em todas as salas de aula da escola lócus deste estudo, há um lembrete que diz: "É proibido o uso de telefone celular na sala de aula das escolas da rede pública estadual de ensino. Parágrafo único. Cabe às escolas definirem as medidas disciplinares aplicáveis aos alunos que infringirem" (ART $1^{\text {o }}$ da Lei $\left.n^{0} 16.993 / 2010\right)$.

Por outro lado, temos grupos que defendem o uso do celular, inclusive utilizando-o como ferramenta pedagógica. $\mathrm{O}$ autor deste artigo se inclui no grupo de professores que defendem essa ferramenta. A escola precisa ser um lugar de inovação. Se olharmos a trajetória educacional no Brasil, vamos ver que a escola que temos hoje (2018), segundo Moran et. al (2013) ainda é um reflexo da escola do passado e, com isso, pautamos nossa prática docente nos velhos métodos, velhos procedimentos e velhos currículos. Frente a isso, os autores sugerem que:

\footnotetext{
a escola precisa reaprender a ser uma organização efetivamente significativa, inovadora, empreendedora. Ela é previsível demais, burocrática demais [...]. Uma educação inovadora se apoia em um conjunto de propostas, [...], com conhecimento integrador [...], desenvolvimento da autoestima e do conhecimento [...], formação de alunos empreendedores (criativos, com iniciativa), [...], de alunos cidadãos. (MORAN, et. al, 2013, p.12-13).
} 
Nessa perspectiva, compreendemos que não é proibindo o uso do celular que vamos fazer da sala de aula um espaço mais eficaz de aprendizagem, até porque, como afirma Kenski (2012, p. 17), “os vínculos entre conhecimento, poder e tecnologias estão presentes em todas as épocas e em todos os tipos de relações sociais". O que temos que fazer enquanto gestores de sala de aula é promover essa interação de forma criativa e prazerosa. Não podemos utilizar um ato isolado de indisciplina, que muitas vezes acontece em sala de aula devido ao uso do celular para justificar o não uso desse aparato tecnológico a favor do processo.

Para melhor contextualização, informamos que este relato nasceu de uma experiência de sala de aula, numa turma de $2^{\circ}$ ano do Ensino Médio, na disciplina de Física. No momento em que o professor fazia a discussão sobre a avaliação e seus respectivos resultados, foi surpreendido por um celular em volume altíssimo que, ao receber uma chamada, tocou a música "Bicicletinha" da banda Kaçamba. Até que o aluno encontrasse o celular em sua mochila, foi ouvida praticamente a música toda, resultando numa sala tomada por risos; muitos risos! O professor, utilizando sua criatividade, passou a explicar os conteúdos de Física, a partir da música que, naquele momento, havia roubado a cena na sala de aula. Tal fato, segundo Bettega (2010, p 29) citando Freire (2000), “enfatiza a importância de se estabelecer uma necessária intimidade, entre os saberes curriculares fundamentais aos alunos e a experiência social que eles têm como indivíduo" (p.29).

Ao redirecionar as atividades de Física para a música em questão, o professor percebeu que os alunos ficaram impactados, pois não imaginariam que a música "Bicicletinha" possibilitaria tantas informações ligadas à Física. O trabalho prosseguiu por mais duas aulas. A sequência didática elaborada pelo professor foi a seguinte: num primeiro momento, os alunos deveriam ouvir atentamente a música; em seguida, promoveu uma discussão na qual os alunos tiveram a oportunidade de falar o que entenderam da música. Feito isso, o professor solicitou que os alunos escrevessem palavras-chave, ou ideias, que pudessem correlacionar a música com o estudo de Física. Como tarefa de casa, os alunos deveriam buscar tal correlação e, na sequência, uma atividade avaliativa.

Muitas vezes nos deparamos com situações em sala de aula que nos levam a refletir sobre o fazer docente, sobre nossas práticas e nossas ações enquanto educadores. A música, mesmo num momento não oportuno, serviu de aparato para o desenvolvendo de uma prática integradora, que partiu de uma ação provocada pelo aluno, foi discutida e trabalhada em sala e tornou-se uma experiência significativa. 


\section{O caminho para a aprendizagem}

Quando pensamos em aprendizagem em seu sentido mais amplo, logo nos vêm à mente as palavras educação e escola, ou vice-versa. Está no imaginário coletivo da sociedade, em todo o seu contexto sócio histórico, que as pessoas vão à escola para aprender. Mas, aprender o quê? Essa questão leva a depreender que o conceito subjetivo de aprendizagem, interligado à ação escolar, tem caráter limitado. Segundo Gil (2015, p.80) esta limitação está no fato do conceito de aprendizagem ser "confundido com o de aquisição de conhecimentos". E vai mais adiante. Gil (2015) explica, que "o conceito de aprendizagem é muito mais amplo, já que se refere a um processo permanente, que se inicia com o início da vida e só termina com a morte” (p. 80).

Do exposto, cabe salientar que o conceito de aprendizagem tem sua base epistemológica nos conhecimentos empíricos da Psicologia, principalmente no behaviorismo. Sem querer adentrar nas concepções históricas e etimológicas da palavra, nos propomos a entender a aprendizagem no dia a dia, no chão da sala de aula, no cotidiano escolar, a partir da relação professor/aluno. Nesse contexto, Gil (2015) salienta que o conceito sobre educação geralmente envolve os significados de: (a) aquisição de conhecimento pela experiência ou atividade intelectual; (b) aquisição de capacidade para fazer, praticar ou empreender uma ação; e (c) desenvolvimento de capacidade para exercer uma profissão.

Sabemos que são muitos os fatores que interferem no processo de aprendizagem, alguns de ordem cognitiva, a exemplo da inteligência e criatividade, e outros, tão importantes quanto, que permeiam fatores diversos, como a motivação, a idade, o sexo, o ambiente social, os hábitos de estudo e a memória do aluno (GIL, 2015, p. 80-81).

A partir dessas ideias, Gil (2013) explicita que as pessoas apresentam diferenças significativas em relação à aprendizagem. Alguns alunos são mais rápidos, outros mais lentos ao atender um determinado comando do professor. Pontua o teórico que a motivação é "algo interior, as pressões externas podem aumentar o desejo de aprender, mas é necessário primeiramente que se queira aprender" (p.58). Complementa que a concentração no processo ensino aprendizagem, "depende muito da motivação". "Mas, a concentração também é influenciada por estímulos do ambiente, como: dimensões da sala de aula, recursos de ensino, sequência de apresentação da matéria, maneirismos do professor, qualidade dos textos de apoio etc." (p.59). 
Na organização do fazer escolar, ou seja, a elaboração do planeamento e das estratégias a serem utilizadas pelos professores, é importante lembrar da diversidade de identidades que povoam esses espaços, bem como que a trajetória de vida desses sujeitos dá a eles heranças diversas e capital cultural diferenciados. Para Tardif e Lessard (2014, p. 196) o processo de ensino-aprendizagem no meio escolar "consiste em perseguir objetivos, ao mesmo tempo de socialização e de instrução, num contexto de interação com os alunos".

Nessa caminhada rumo à aprendizagem, um elemento importante são as vozes presentes em sala de aula, que precisam ser redirecionadas e incorporadas ao fazer pedagógico. As vozes se convergem nas relações dialógicas estabelecidas entre professor e alunos, fazendo uma interação/integração entre vivências e conhecimentos, entre trajetórias de vida e currículo real.

As relações dialógicas, ou voz pedagógica, pressupõe que o diálogo entre aprender e ensinar acontece em mão dupla. O sucesso do fazer pedagógico em sala de aula está na forma como as estratégias ou técnicas pedagógicas são utilizadas nesses espaços. Corroborando com essa ideia, Anastasiou (2004, p.71) enfatiza que "as estratégias visam à consecução de objetivos, portanto, há que ter clareza sobre aonde se pretende chegar com elas".

No estudo em questão foi utilizada a música como estratégia de ensino. Embora não tenha sido uma estratégia planejada pelo professor, ao utilizá-la ele redirecionou seu planejamento e deu as coordenadas de como deveria ser feito o trabalho, de modo a integrar a música e suas ideias ao currículo de Física do Ensino Médio.

Segundo Gilio, (2000, p.12) “a música é um recurso didático simples, dinâmico, contextualizado, que se aproxima da realidade do jovem, ajudando no diálogo entre professor e aluno e favorecendo a interdisciplinaridade". O sucesso da prática executada pelo professor está exatamente no olhar de interdisciplinaridade e transversalidade que deu à dinâmica (estratégia) e na maneira como reorganizou sua prática de forma coordenada, explicitando claramente qual o objetivo a ser atingindo a partir daquele contexto e, ainda, no aproveitamento de um elemento "trazido" pelo aluno, de sua vivência, de sua cultura e conhecimento.

\section{Metodologia}

Este estudo caracteriza-se como pesquisa de natureza descritiva na qual, segundo Andrade (2010, p,112), os fatos são observados, registrados, analisados, classificados e 
interpretados, sem que o pesquisador interfira neles. Uma das características básicas da pesquisa descritiva é a observação sistemática seguida do caráter exploratório, norteada pelo método da pedagogia histórica crítica, que procede da teoria dialética do conhecimento, defendida por Gasparin (2002).

Em seu sentido mais amplo, o pesquisador também se utilizou dos princípios da pesquisa participante, "por meio da partilha do saber envolvendo questões teóricas, metodológicas e práticas diretamente relacionadas à participação ativa das pessoas" (BRANDÃO e STRECK, 2006, p.9).

Segundo Figueiredo (2004, p. 60), “aproximar música e pedagogia pode representar uma alternativa para que a educação seja compreendida, solicitada e aplicada sistematicamente".

Para estruturação e execução das ideias, o trabalho foi dividido nas seguintes etapas:

Etapa 1 - Ouvir a música; Etapa 2 - Leitura e interpretação da letra da música; Etapa 3 - Estudo contextual - relação entre a música e a disciplina de Física (extração de palavraschave); Etapa 4 - Promover o diálogo entre as palavras-chave e os conhecimentos da física.

\section{Resultados e discussões}

O presente estudo nasceu de uma experiência vivenciada em sala de aula do $2^{\circ}$ ano do ensino médio em uma escola pública estadual em Goiás, que estabeleceu uma relação entre a prática e o fazer pedagógico a partir da realidade da sala de aula. Descreve um contexto que, em meio a uma explicação de conteúdos, professor e turma são surpreendidos com o toque de um celular tendo ao fundo a música "Bicicletinha", cuja letra apresentamos abaixo.

Bicicletinha (BANDA KAÇAMBA)

\footnotetext{
Ela sai de saia de bicicletinha

Uma mão vai no guidão a outra tapa na calcinha (bis)

Me dá um arrepio quando ela sai pedalando,

Mas tem uma mão na frente que tá sempre atrapalhando,

Mas acho que ela tem medo do periquito voar

Por isso que ela não para de tampar (bis)

Eu não aguento mais essa situação

Vamos liberar geral, vamos tirar essa mão

Bota saia e vem pra rua
} 
(Disponível em: https://www.letras.mus.br/banda-kacamba/1485537/acessado em 23 de jun. de 2018)

Depois de ouvir a música, o professor convidou a turma para fazer a leitura e interpretação de sua letra. Pediu também que os alunos fizessem uma relação entre a música e a disciplina de Física, solicitando que eles retirassem palavras chave que pudessem correlacioná-las. Algumas das palavras retiradas estavam visíveis no texto, outras subtendidas, ficando estruturadas da seguinte maneira:

\section{Relação entre a física e a música bicicletinha}

\begin{tabular}{c|c|l}
\hline Música & \multicolumn{1}{|c}{ Conteúdos abordados } \\
\hline BICICLETA & Cinemática & $\begin{array}{l}\text { 1-Estudo dos Movimentos. } \\
\text { Uniforme; } \\
\text { Uniformemente variado; } \\
\text { Circular. }\end{array}$ \\
& Dinâmica & $\begin{array}{l}\text { Newton. } \\
\text { Neça e as Leis de }\end{array}$ \\
& Estética & $3-$ Equilíbrio \\
& Acústica & $4-$ O som \\
& Óptica & $5-$ As cores \\
\hline
\end{tabular}

Fonte: Própria pesquisa/2018

Feita a correlação entre a música e a Física, a tarefa de casa foi que os alunos procurassem uma explicação coesa dessa correlação. O resultado apresentado a seguir é uma junção da pesquisa feita pelos alunos, complementada pelo professor.

1. A primeira ideia evocada pelos alunos relacionada à palavra bicicleta foi seu uso como meio de transporte alternativo que traz benefícios para o ciclista e também para a comunidade e o meio ambiente; Sobre a relação da bicicleta com a Física, pontuaram os seguintes conteúdos: 
Estudo dos movimentos - segundo Fukui (2016, p.41) a parte da Física que estuda os movimentos dos corpos é chamada de Mecânica. Está dividida em três partes, a saber:

a) Cinemática: descreve o movimento dos corpos sem considerar suas causas. Tomando como exemplo a bicicleta se deslocando por uma estrada, a Cinemática aborda algumas características desse movimento, como: referencial, trajetória, espaço, deslocamento escalar, distância percorrida e tempo de duração do percurso. (Idem, p.41).

- $\quad$ Referencial - é um corpo ou uma posição de referência, utilizados para identificar se um corpo está em movimento ou em repouso em relação a esse referencial (idem, p.42)

- Trajetória - é o lugar geométrico das diversas posições ocupadas por um corpo em movimento em relação a um referencial (idem, p.43).

- $\quad$ Espaço - é uma grandeza escalar que permite localizar um ponto material em uma trajetória conhecida que possui origem e orientação (idem, p. 44).

- Deslocamento escalar - é uma grandeza escalar que representa a variação do espaço de um corpo em uma trajetória, em um certo intervalo de tempo (idem, p. 45).

- Distância percorrida - é a soma dos módulos dos deslocamentos parciais realizados pelos corpos. No caso de o corpo realizar um movimento em um único sentido da trajetória, a distância percorrida corresponde ao módulo do deslocamento escalar nesse trajeto (idem, p. 45).

- Velocidade escalar média - expressa a velocidade que, se fosse constante, ocorreria no mesmo deslocamento escalar sofrido pelo corpo no mesmo instante de tempo considerado (idem, p. 46).

- Movimento uniformemente variado (MUV) - é aquele no qual a variação da velocidade é a mesma para intervalos de tempo iguais (idem, p. 64).

- Aceleração escalar média - é a grandeza que indica a variação da velocidade escalar em determinado intervalo de tempo (idem, p.65).

b) Dinâmica: estuda as causas dos movimentos (FUKUI, 2006 pp.104-142)

- $\quad$ Força como interação;

- Natureza das interações;

- $\quad$ Efeitos das forças;

- A inércia e a primeira Lei de Newton;

- $\quad$ Segunda Lei de Newton;

- Impulso e Colisões.

c) Estática: estuda as condições para que um corpo fique em repouso (FUKUI, 2006, pp. 214-222).

- Equilíbrio;

- Relação entre equilíbrio e força;

- Corpo extenso;

- Força em um corpo extenso e braço da alavanca. 
d) Movimento Circular uniforme - é todo movimento cuja trajetória é uma circunferência ou um arco de circunferência e que tem as seguintes características: velocidade escalar, velocidade angular, frequência e período constante (FUKUI, 2016, p. 88).

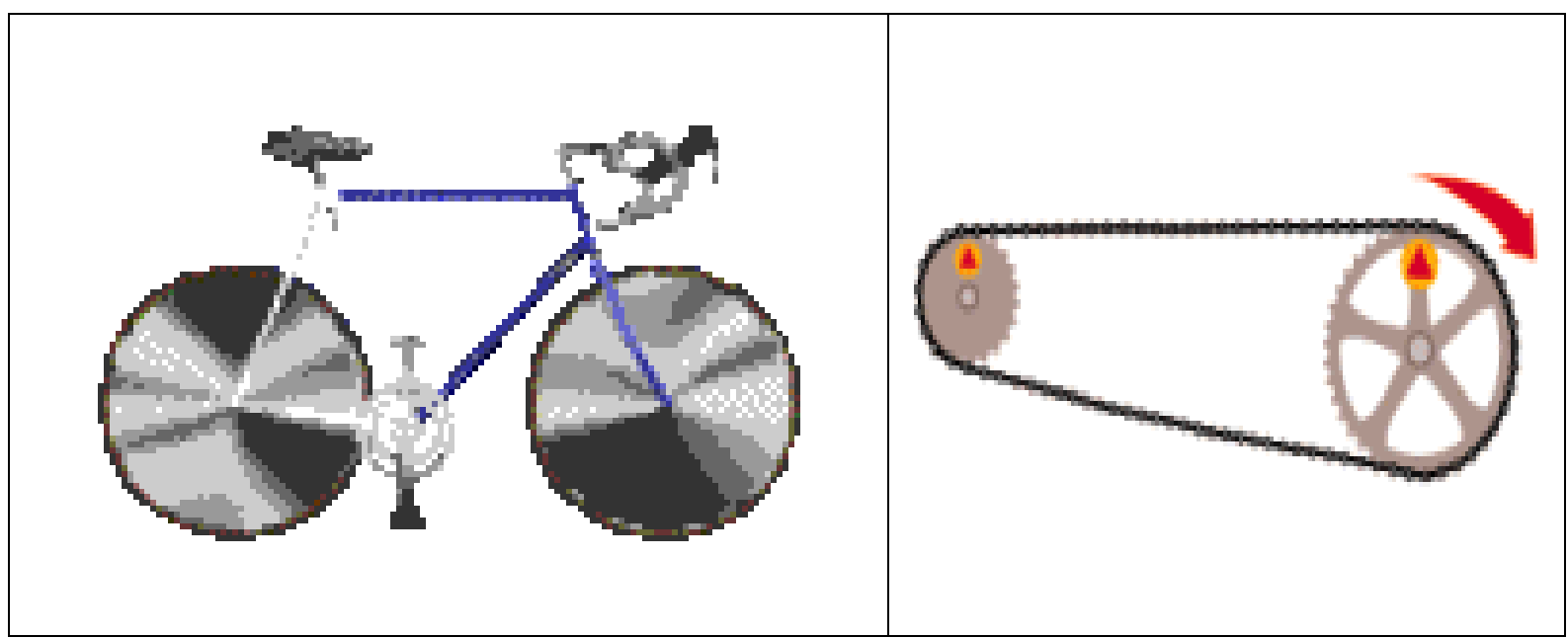

Disponível em: www.lucianofeijao.com.br/clf/clique professor/exatas/8/.../20130317221923.ppt, acessado em 23 de jun. de 2018.

Partindo das concepções de Fukui (2016, p.91), a transmissão de movimento circular pode ser feita por contato direto entre duas rodas, ou por meio de uma corrente ou correia que as conecta. Tanto por contato direto como por corrente, são usadas rodas dentadas para evitar o deslocamento entre as rodas, uma vez que os dentes se encaixam nos sulcos da outra roda ou nos elos da corrente.

Máximo e Alvarenga (2011, p.92), afirmam que o tempo que a partícula gasta para efetuar uma volta completa, o denominado período do movimento, é representado por T. O espaço percorrido pela partícula, durante um período, é o comprimento da circunferência, que vale $2 \pi R$ ( $R$ é o raio da trajetória).

2. A segunda palavra surgida a partir da música bicicletinha foi equilíbrio. Quando correlacionada com os estudos da Física, encontramos em Fukui (2016, p. 220) as seguintes informações:

a) Os corpos podem ser equilibrados quando apoiados em um único ponto, mas é preciso que esse ponto coincida com seu centro de massa (p.220).

b) O centro de massa (CM) de um corpo, ou de um sistema de corpos, é um ponto no qual se considera que está concentrada toda a massa do corpo, ou sistema, de modo 
que, quando forças externas atuam sobre ele, tudo acontece como se a resultante fosse aplicada nesse ponto (p.220).

c) As alavancas são usadas para mover objetos que estejam apoiados em algum ponto ao longo do instrumento. Elas podem também reduzir o esforço ou intensificar o efeito da aplicação de uma força; são constituídas de pelo menos uma barra e um ponto fixo de apoio. Os freios da bicicleta são constituídos por sistemas de alavancas (p. 222).

3. Outra palavra escolhida pelos alunos, foi “cores". As cores também são objeto de estudo da Física. Segundo Fukui (2016, p.205) é possível responder as perguntas: por que os objetos apresentam cores diferentes? Para que um objeto seja visto, deve refletir a luz de alguma fonte primária, que em muitas situações emite luz branca mas que não faz com que todos os objetos sejam vistos como brancos. Por quê?

A resposta para essas questões, Fukui (2016), foi buscar em Isaac Newton, lá no século XVII, quando demonstrou que a luz branca é composta de luzes de diversas cores. Usando um prisma, ele provou que a luz branca pode ser decomposta em feixes de luz de cores diferentes (idem, p. 206).

Para a autora, um objeto pode absorver a luz de algumas cores e refletir a de outras cores, e é essa luz refletida que os olhos captam (FUKUI, 2016, p.2006).

4. A palavra extraída a partir da música foi o "som”. Os fenômenos sonoros, na Física, estão relacionados com as vibrações dos “objetos materiais". Esses objetos são fontes sonoras que, ao vibrar, produzem ondas que se propagam no meio material (sólido, líquido ou gasoso), situadas próximas à orelha. Ao penetrar na orelha, essas ondas provocam vibrações que nos causam as sensações sonoras (MAXIMO e ALVARENGA, 2011).

Nas linhas dessas ideias, Moreira, Santos e Coelho (2014), pontuam que som são vibrações sonoras regulares enquanto que ruídos são as vibrações irregulares. Pontuam, ainda, que melodia é "a sucessão rítmica e bem ordenada de sons" (p.45).

\section{Considerações Finais}

Este estudo teve como caráter principal relatar uma experiência vivenciada em sala de aula, envolvendo o uso do celular (aqui em alguns pontos apresentados como tecnologia móvel) e o espaço de sala de aula. Mesmo não sendo liberado em sala de aula, é utilizado pela maioria 
dos alunos. O uso do celular divide opiniões entre os educadores e aparece como um dilema a ser superado. Neste trabalho, o foco não era exatamente as tecnologias - embora acredito, enquanto professor pesquisador, na sua importância para o processo de ensino aprendizagem , mas sim em estratégias que podem ser utilizadas criativamente diante de situações diversas com as quais convivemos em sala de aula.

No relato, a música do celular no momento da explicação do conteúdo de Física, poderia vir a ser o início de um estopim, desses que tornam conflituosa a relação professor aluno, ou, ainda, causar constrangimentos ou preconceitos quanto ao tipo de música preferido pela turma. O dito popular da língua de Camões "se a vida te dá um limão, faça uma limonada" pode explicar muito bem essa situação. Precisamos aprender a trabalhar os momentos em sala de aula, transformando-os sempre em momentos positivos e proveitosos.

Por meio dessa atividade, advinda a partir de uma canção popular "Bicicletinha" e do envolvimento dos alunos, foi possível não apenas minimizar a indisciplina e esvaziar conflitos, mas, principalmente, perceber que estratégias diferenciadas desenvolvidas em sala de aula podem tornar o aprendizado mais significativo. Nesse relato em questão, a estratégia partiu de uma música que, quando bem trabalhada, pode desenvolver o raciocínio e a criatividade.

\section{Referências}

ANASTASIOU, Léa das Graças Camargos; ALVES, Leonir Pessate. (Orgs). Processos de ensinagem na universidade: pressupostos para as estratégias de trabalho docente em aula. 6 . ed. Joinville: Univille, 2004.

ANDRADE, M. M. de. Introdução à metodologia do trabalho científico. 10. ed. - São Paulo: Atlas, 2010.

BETTEGA, M. H.S. A educação continuada na era digital. 2. ed. - São Paulo: Cortez, 2010.

BRANDÃO, C.R; STRECK, D.R. Pesquisa participante: a partilha do saber. 1. ed. Aparecida, SP: Ideias Et Letras, 2006.

FIGUEIREDO, Sérgio Luiz Ferreira. A preparação musical de professores generalistas no Brasil. Revista da ABEM, v. 11, p. 55-62. Porto Alegre: 2004.

FREIRE, P. Educação como prática da liberdade. 24a ed. Rio de janeiro, Paz e Terra. 2000. 
FUKUI, A; MOLINA, M.M. (Org.). Física, $1^{0}$ ano. 3. ed. - São Paulo: Edições SM, 2016.

GASPARIN, João Luiz. Uma Didática para a Pedagogia Histórico-Crítica. 3. ed. Campinas, SP: Autores Associados, 2002.

GIL, Antônio Carlos. Didática do ensino superior.1. ed. -9. reimpr. São Paulo: Atlas, 2015. (SÓ SEIS ESPAÇOS, MARCELO) Metodologia do Ensino Superior. 4. ed. - 8. reimpr. São Paulo: Atlas, 2013.

GILIO, A.M.C. Pra que usar de tanta educação para destilar terceiras intenções?: jovens, canções e escola em questão. Movimento: Revista da Faculdade de Educação da UFF, Niterói, n.1, 2000.

KENSKI, V.M. Educação e tecnologias: o novo ritmo da informação. 8. ed. - Campinas, SP: Papirus, 2012.

MÁXIMO, A; ALVARENGA, LUZ, R. da Luz; ALVARENGA, B. Coleção de física contexto \& aplicações. 1. ed. - São Paulo: Scipione, 2011.

MORAN, J.M; MASETTO, M.T; BEHRENS, M.A. Novas tecnologias e mediação pedagógica. 21. ed. Ver. e atual. - Campinas, SP: Papirus, 2013.

MOREIRA, A.C; SANTOS, H; COELHO, I.S. A música na sala de aula - a música como recurso didático. UNISANTA Humanitas - p. 41-61; Vol. 3 nº 1, (2014)

Museu Escola do IB. Universidade Estadual Paulista. Como as aves voam? São Paulo. http://www2.ibb.unesp.br/Museu_Escola/Ensino_Fundamental/Animais_JD_Botanico/aves/a ves_biologia_geral_voo.htm, Acessado em 23 de jun. de 2018.

TARDIF, M. LESSARD, C. O trabalho docente: elementos para uma teoria da docência como profissão de interações humanas. 9. ed. - Petrópolis, RJ: Vozes, 2014.

Como citar este artigo (Formato ABNT):

PURIFICAÇÃO, Marcelo Máximo; CATARINO, Elisângela Maura; TEIXEIRA, Maria Filomena Rodrigues; SANTANA, Maria Luzia da Silva. A Música como Ferramenta Pedagógica: Relato de uma Experiência nas Aulas de Física no Ensino Médio. Id on Line Rev.Mult. Psic., 2018, vol.12, n.42, p. 249-260. ISSN: 1981-1179.

Recebido: $13 / 08 / 2018$;

Aceito: 06/09/2018 